\title{
Personality Types and Patterns of Marital Conflict among Married Staff of Selected Universities in Southwest Nigeria
}

\author{
Johnson O. Agboola ${ }^{1} \&$ Sehinde A. Oluwatosin ${ }^{1}$ \\ ${ }^{1}$ Department of Educational Foundations \& Counselling, Obafemi Awolowo University, Ile-Ife, Osun State, \\ Nigeria \\ Correspondence: Johnson O. Agboola, Department of Educational Foundations \& Counselling, Obafemi \\ Awolowo University, Ile-Ife, Osun State, Nigeria.
}

Received: August 3, 2020

Accepted: August 24, 2020

Online Published: August 26, 2020

doi:10.5539/ijps.v12n3p37

URL: https://doi.org/10.5539/ijps.v12n3p37

\begin{abstract}
This study investigated the personality types and patterns of marital conflict among the staff of universities in southwest Nigeria. The study adopted a descriptive survey design. 1330 married staff members, proportionately selected from nine universities, using a multi-stage sampling technique, constituted the study sample. Prevalence of Patterns of Marital Interaction Questionnaire (PPMIQ) and Personality Type Questionnaire (PTQ) were used to collect data for the study. The results showed that $67.1 \%$ of the staff indicated that they experienced demand-withdraw pattern, while $26.8 \%$ experienced constructive pattern. Only $6.1 \%$ experienced a destructive pattern. The results also showed that the largest percentage of the staff $(20.3 \%)$ indicated that the possessed Introverted Intuitive personality while $16.9 \%$ and $16.8 \%$ demonstrated Extroverted Thinking and Extroverted Feeling personalities respectively. The smallest percentage $(1.9 \%)$ demonstrated Introverted Sensational Personality. Also, from the result of this study, it is obvious that married staff in universities in southwest Nigeria have one form of marital conflict or the other. Furthermore, based on the results of the analysis, it could be concluded that all three patterns of marital conflict are being experienced by the married staff. The demand-withdraw pattern, however, appeared to be the typical pattern among the married staff.
\end{abstract}

Keywords: marital conflict, patterns, personality types, staff, universities

\section{Introduction}

Personality types may be described as the grouping of individuals based on how they differ in gathering information, process information, reach conclusions and their communication styles. Personality type, therefore, may be related to patterns of marital conflict in several ways. McAdams (as cited in Bono, Boles, Judge \& Lauver, 2002) opined that differences in individual personality types may be described at three levels. Level one involves a person's personality type. Level two involves what a person does (contextually influenced strategies, goals, and concerns). Level three involves how the person makes meaning of his or her experiences-life narratives.

Consequently, certain personality types may likely be associated to some particular conflict motives and resultant specific behavior patterns. Mulligan (2015) stated that people generally tend to reflect the strengths of their personality types in everyday interactions within their comfort zone. In other words, many conflict interactions may be stressful and at such times, people may revert to behavior more typical of their preferred type. Differences in personality types can lead to misunderstanding and hostility between couples, where not well managed. Similar personalities, Pienaar (2004) opined can also create the same impact, but less often and for different reasons.

As no two individuals are totally the same, it is necessary therefore for couples to know from an initial point in their marriage that opposites do indeed attract and that they can also drive each other apart. This understanding becomes necessary because personality types may result in different communication styles, which if not properly managed may cause conflict. Thus, the ability of couples to understand and be able to talk about their differences and types would be of great importance in their day-to-day interaction and by extension help diffuse personality clashes among them. Moreover, happiness and ability to get along in marriage are likely to be dependent on how well each spouse understands his or her partner's temperament and how is he or she willing to meet the partner's temperament needs. However, the real impact of these personality types on patterns of marital conflict among 
married university staff in southwest Nigeria is not known. This study would attempt to investigate the outcome of such a match concerning the conflict situation in marital relationships. The knowledge of such would provide useful information to marriage counsellors in remediation and prevention of marital conflicts.

\subsection{Personality Types}

There are many versions of personality types but data gathering for this study focused on Jung's (1971) classification into eight personality sub-types and their respective characteristics. They are introverted thinking, introverted feeling, introverted sensational and introverted intuitive. The others are extroverted thinking, extroverted feeling, extroverted sensational and extroverted intuitive. According to Jung (1921/1971) differences in behavior result from peoples' inborn tendencies to use their minds in different ways. As people act on these inclinations, they establish patterns of behaviors.

In order to explain this characterisation of types, Jung developed the concepts of attitudes and functions. The former refers to the way a person either directs psychic energy, inwardly or out toward the external world. The latter idea refers to how we make sense of the world around us, which capabilities we rely on most heavily or prefer (Myers \& McCaulley, as cited in Pienaar, 2004). In other words, libido, the life energy, as stated by Jung, may flow in two directions-inward or outward. Jung explained further that the individuals in whom the life energy flows inward are regarded as introvert, while those in whom life flows outward are termed as extroverts. In addition, Jung associated a person's introvert and extrovert orientations with four main behavioural functions, namely, thinking, feeling, sensation, and intuition, resulting in the following eight personality types: Introverted Thinking Type, Extroverted Thinking Type, Introverted Feeling Type and Extroverted Feeling Type. Others are Introverted Sensational Type, Extroverted Sensational Type, Introverted Intuitive Type and Extroverted Intuitive Type (Mangal, 2005).

For each of the types, each person has a natural, inborn preference for one side or the other. The concept of preferences can be illustrated by asking someone to write his or her name, first with the normal writing hand and then with the other hand. Describing the two experiences, people emphasise that the first is comfortable, natural, fast, and done without concentration. The second experience is described as the opposite on all accounts. People admit they can write with their non-preferred hands, but it takes more effort and concentration, and the results are not as good. In the same way, when people use their psychological preferences, tasks come more naturally and people feel more confident, competent, and at ease. They can use their non-preference but tend not to, since it takes more effort and concentration (Myers, 1998).

The eight different personality types as explained by Sandhu and Kapoor (2013) are presented as follows: Extroverted Thinking - These are the people who understand the world through a mix of concrete ideas and abstract ones, but the abstract concepts are ones passed down from other people. Introverted Thinking - These people interpret stimuli in the environment through a subjective and creative way. The interpretations are formed by internal knowledge and understanding. Extroverted Feeling - These people judge the value of things objectively. They are comfortable in social situations, they form their opinions based on socially accepted values and beliefs of the majority. Introverted Feeling - These people make judgments subjectively and on internally established beliefs. They ignore prevailing attitudes often and defy social norms of thinking. Extroverted Sensing - These people perceive the world as it exists. Their perceptions are not influenced by any pre-existing beliefs. Introverted Sensing - These individuals interpret the world through the lens of subjective attitudes and rarely see something for only what it is. Extroverted Intuitive - These people understand the meanings of things through subliminally perceived objective fact rather than incoming sensory information. Introverted Intuitive - This comprises individuals who are strongly influenced by their internal motivations even though they do not completely understand them.

In applying the types to marital relationships, Mulligan (2015) highlighted behaviours that tend to be associated with each personality preferences and which may appear during conflict or create difficulties in communication. The characteristic behaviours, as outlined by him, are replicated as follows:

\section{Introvert}

- May not say enough - may miss the opportunity to speak and regret it

- Most often at a disadvantage when conflict erupts - need time to reflect before responding

- Like advance notice of issues and time to prepare/ rehearse before interaction

- May want to withdraw inside themselves when conflict takes them by surprise 


\section{Extrovert}

- May not listen enough -too full of what they want to say

- Talk louder and faster - clarify their viewpoint as they talk

- If they can say "just one more thing" it will be sorted - may say too much

- Want to talk out problems now - may get frustrated/ panicky if they can't

Thinking

- Tend to get too analytical/ task focused in a dispute - fail to attend to impact on people

- Logical arguments may have little to do with hurt feelings involved

- "Try not to get emotional" tactic - may miss own and other's emotional signals and needs

- Tells the story from outside experience - disassociated/ objective - seem cold/ unsympathetic

Feeling

- Tend to personalise everything - even things that were not meant to be personal - blame self or others, may overlook context.

- View conflict as a behaviour to be side-stepped - tend to give in before issue is resolved to re-establish harmony

- Tell the story from the inside experience - what it feels like - but difficult to stand back

- May confuse how it is with how they are feeling

Sensing

- Like to argue the facts - the more specific the better. Search for truth may distract from what is most important

- Prone to side-track bigger issue by focussing on details of less relevant issues

- More concerned with sorting the present hurt/injustice than creating a better future

- May miss the undercurrents - what lies behind the words/ between the lines

Intuiting

- Tend to make broad generalisations - may inflate specific incident to sweeping pattern

- See sensors emphasis on facts as nit-picking, irrelevant

- May miss the obvious or 'forget' inconvenient details

- Prone to seeing 'half empty glass' - what is missing/ not being addressed and miss what is

\subsection{Marital Conflict Patterns}

The concept of marital conflict had been extensively discussed by different researchers. In this paper, however, the concept will be discussed from the perspective of Gottman's (1994) Theory of Balance. Gottman (1994) came up with a typology of marital conflict after carrying out broad research with married couples. The research had to do with observing and recording couples' verbal and nonverbal conflict behaviors as well as their physiological response to conflict. The extent to which a couple fought, Gottman research revealed, was inconsequential when compared to how they quickly resolve their differences, after every fight. Consequently, marriage would become stable and enduring if couple learn how to settle their differences as quickly as possible (Butler, 2006). Gottman's theory allowed conflict behavior to be understood from the perspective of a couple's typical pattern of interaction.

Gottman and his associates witnessed couples in conflicted conversations, and from their observations grouped couples into four different types (Gottman, 1999; Gottman \& Levenson, 1998). The four different types of couples are namely: conflict-avoiding couples, volatile couples, validating couples and hostile couples. Gottman labelled the first three types of couples as regulated couples while the remaining one was tagged as non-regulated couples. The regulated couples, Gottman explained, were able to adjust their affect and relations to the point that they repeatedly showed more positive than negative communications during a conflict and seemed to have stable relationships with lower risks of divorce. On the other hand, non-regulated couples, Gottman observed, showed fewer positive communications and appeared to be heading toward divorce. 
Gottman (1994) maintained that the four types of couples were qualitatively different from each other, though similar underlying processes determine their stability. He proposed a "theory of balance" in which the total proportion of positive to negative exchanges overtime, was responsible for the stability or instability of the four couple types. For instance, Gottman found that regulated couples demonstrated a ratio of about five positive interactions for every single negative interaction while non-regulated couples demonstrated closer to a one-to-one ratio. To substantiate this finding, Gottman, acknowledged that the work of Raush, Barry, Hertel, and Swain (1974) formed the basis for his conceptualisation of couple conflict patterns. These patterns, according to him, are relatively stable over time.

Furthermore, Gottman (1994) posited that there were three types of problem-solving approaches in healthy marriages. These were conflict-avoiding, volatile and validating. According to him, these three mentioned approaches can lead to stable and enduring marriages. However, the fourth approach, which he subdivided into hostile and hostile/detached, is likely to end in divorce. Overtime, researchers like Pasch and Bradbury (1998), Crohan (1996) and Kurdek (1995), labelled patterns of marital conflict as constructive, destructive and withdrawal. These latter categorisations will be adopted in answering research question 1.

A description of the four approaches as identified by Gottman (1994) is presented below.

\subsubsection{Conflict-Avoiding Couples}

Gottman (1994) noted that conflict-avoidance has been seen by researchers as dysfunctional but his research showed it can be functional. He stated that these couples may be more accurately conceptualised as minimising conflict rather than avoiding it altogether.

According Busby and Holman (2009) an avoidant style of conflict does not mean partners have withdrawn from the relationship. These two researchers were of the opinion that avoidant couples prefer to cope with conflict by not dealing with it directly and letting time resolve most problems. Couples with avoidant conflict style still engage in positive relationship experiences even if they prefer to avoid overt conflict (Busby \& Holman, 2009). Regardless of these relationship experiences, Gottman asserted that loneliness may be a risk for conflict-avoiding couples as they express very little negative affect but also little positive affect. He, therefore, expressed worry that unavoidable quarrels could arise between this type of couples conflicts. Regrettably, such couples may not possess the requisite conflict resolution or management strategies. Eventually, these types of couples may degenerate to a non-regulated antagonistic or hostile type of interaction (Gottman, 1994).

\subsubsection{Volatile Couples}

This type of couples depicts another scenario, manifesting both positive and negative interactions, high emotionality, and high expressiveness in both partners. Gottman (1994) observed that volatile couples have explosive conflicts followed by passionate resolution and making-up. These couples engage in strong persuasion attempts throughout their conflicts, especially as they first begin a conflict discussion. Gottman noted that volatile couples are usually able to use their positive interactions to repair negative exchanges, but expressed concern that some negative interactions may be too hurtful to repair; if this occurred, volatile couples also run the risk of deteriorating into a non-regulated hostile type of relationship (McCarthy, 2006).

\subsubsection{Validating Couples}

These couples are emotionally close, have a high degree of "we-ness", practice verbal openness and communication, display much affection, share as much time together as possible, are interested in one another, attempt to understand the partner's opinion, etc. (Bodenmann, Gottman \& Backman, 1997). These researchers further explained that validator couples' interaction is characterised by calm discussions and a great deal of positive feedback channeling. They concluded that these couples' communication of emotions tends to be less strong and obsessive than that witnessed in volatile couples.

\subsubsection{Hostile Couples}

Gottman classified non-regulated couples into two types. These are hostile couples and hostile/detached couples. Hostile couples could be identified by manifesting a high level of disagreement and excessive sensitivity to criticisms. Hostile/detached, Gottman (1994) opined, are usually disconnected. They nevertheless, have short-lived incidents of destructive relationships. In addition, they manifest hatred and aversion for each more than hostile couples. He suggested that the hostile/detached couple type may represent a further deterioration of the hostile couple type. Gottman has often grouped with the two types of non-regulated couples, as did the authors of a survey based on his conception of coupe conflict types (Holman \& Jarvis, 2003). 


\section{Objectives of the Study}

The objectives of the study are to:

i. determine the patterns of marital conflict among the married staff of selected universities in Southwest Nigeria;

ii. identify the personality types that are associated with patterns of marital conflict among the married staff of selected universities in Southwest Nigeria.

iii. determine the influence of each personality type on patterns of marital conflict among the married staff of selected universities in southwest Nigeria.

\subsection{Research Questions}

i. what are the patterns of marital conflict among the married staff of selected universities in southwest Nigeria?

ii. Which personality types are associated with the patterns of marital conflict among the married staff of the selected universities in southwest Nigeria?

iii. What is the influence of each personality type on patterns of marital conflict among the married staff of selected universities in southwest Nigeria?

\section{Method}

Using Sample Size Table from the Research Advisors (2006), as a guide, the study sample consisted of 1330 married staff members proportionally selected from nine universities. Multi-stage sampling technique was employed to select the sample for this study. Three out of the six states in southwest Nigeria were selected by means of a simple random sampling technique. In each of the three states, three universities were selected by means of a stratified sampling technique. Ownership was used as the basis for stratification. The universities were categorised as follows: Federal, State, and Private universities. This gave nine universities altogether for the study. Respondents were proportionally selected based on the staff population of each university. Five faculties were selected in each of the universities by means of a simple random sampling technique. Respondents from each faculty were selected by means of convenience sampling techniques.

Two instruments titled "Patterns of Marital Interaction Questionnaire (PMIQ)" and "Personality Types Questionnaire (PTQ)" were used to collect data. The PMIQ was adapted from three standardised instruments titled: "Conflict Tactics Scale (CTS; Straus, 1979), "Gottman Sound Relationship House Questionnaires-Constructive versus Destructive Conflict Measure" (Gottman, 1999) and "Gottman Sound Relationship House Questionnaires-The Three Relationship Processes" (Gottman, 1999). The original versions of the instruments were made up of 19, 103 and 55 items respectively. The items covered compromise, negative sentiments override, effective repair attempts, harsh startup, the four horsemen, accepting influence, flooding and gridlock on perpetual issues. The adapted version contained information collected from related literature. It had two sub-sections as follows: B (i) and B (ii). Sub-section B (i) explained three major patterns of marital conflict namely: constructive, destructive and demand/withdraw. Sub-section B (ii) had 20 items formulated to elicit information on couples' patterns/frequency of marital conflict. The questionnaire was scored using a four-point Likert rating scale with 3 tagged "Always", 2 "Sometimes", 1 "Rarely" and 0 "Never".

The PTQ has eight sub-scales on personality types. The sub-scales were formulated using materials adapted from Mangal's (2005) description of Jung's (1971) classification into eight personality sub-types and their respective characteristics. They are introverted thinking, introverted feeling, introverted sensational and introverted intuitive. The others are extraverted thinking, extraverted feeling, extraverted sensational and extraverted intuitive. Altogether, it contained 31 items that sought to elicit information on the respondents' personality types. Scores were determined using a four-point Likert rating scale with 4 being "strongly agree", 3 "agree", 2 "disagree" and 1 "strongly disagree".

Data were collected by the researcher and six field assistants, who have undergone training on how to administer the questionnaires. The questionnaires were administered to 1,330 married staff members. A total of 1,100 of the respondents returned the questionnaire. Data collected were analysed descriptively using percentage scores, frequency counts, Relative Significance Index (RSI), k-means cluster analysis and Multinomial Logistic Regression (MLR) analysis. 


\subsection{Results}

3.1.1 Research Question 1: What are the Patterns of Marital Conflict among the Married Staff of Selected Universities in Southwest Nigeria

To answer this research question, three approaches were adopted. In the first approach, the responses of the selected staff to the section B of the questionnaire were analysed descriptively using percentages and Relative Significance Index (RSI) and the result is as presented in Table 1.

Table 1. Patterns of marital interaction during conflicts

\begin{tabular}{|c|c|c|c|c|c|c|c|c|c|c|c|c|c|}
\hline & \multirow{2}{*}{$\begin{array}{l}\text { Items on the pattern of marital } \\
\text { conflict. } \\
\text { How frequently does my } \\
\text { spouse.....? }\end{array}$} & \multicolumn{2}{|c|}{ Always } & \multicolumn{2}{|c|}{ Sometimes } & \multicolumn{2}{|c|}{ Rarely } & \multicolumn{2}{|c|}{ Never } & \multicolumn{2}{|c|}{ No response } & \multirow[t]{2}{*}{ RSI } & \multirow[t]{2}{*}{ Rank } \\
\hline & & $\mathrm{F}$ & $\%$ & $\mathrm{~F}$ & $\%$ & $\mathrm{~F}$ & $\%$ & $\mathrm{~F}$ & $\%$ & $\mathrm{~F}$ & $\%$ & & \\
\hline 1 & Yells at me & 79 & 07.3 & 255 & 23.5 & 318 & 29.3 & 388 & 35.8 & 45 & 04.1 & 0.506 & 11 \\
\hline 2 & $\begin{array}{l}\text { Gives up quickly to end an } \\
\text { argument }\end{array}$ & 333 & 30.7 & 379 & 34.9 & 270 & 24.9 & 80 & 07.4 & 23 & 02.1 & 0.727 & 6 \\
\hline 3 & Hurts me with some objects & 42 & 03.9 & 136 & 12.5 & 131 & 12.1 & 752 & 69.3 & 24 & 02.2 & 0.375 & 17 \\
\hline 4 & Withdraws from arguments & 333 & 30.7 & 424 & 39.1 & 187 & 17.2 & 109 & 10.0 & 32 & 02.9 & 0.733 & 5 \\
\hline 5 & Pushes me down & 50 & 04.6 & 105 & 09.7 & 136 & 12.5 & 762 & 70.2 & 32 & 02.9 & 0.368 & 18 \\
\hline 6 & $\begin{array}{l}\text { Is good at resolving our } \\
\text { differences }\end{array}$ & 527 & 48.6 & 383 & 36.3 & 100 & 09.2 & 45 & 04.1 & 30 & 02.8 & 0.830 & 2 \\
\hline 7 & Criticises my personality & 79 & 07.3 & 217 & 20.0 & 335 & 30.9 & 424 & 39.1 & 30 & 02.8 & 0.488 & 12 \\
\hline 8 & $\begin{array}{l}\text { Keeps quiet during } \\
\text { disagreements }\end{array}$ & 265 & 24.4 & 458 & 42.2 & 216 & 19.9 & 124 & 11.4 & 22 & 02.0 & 0.703 & 8 \\
\hline 9 & Slaps my face & 47 & 04.3 & 71 & 06.5 & 129 & 11.9 & 812 & 74.8 & 26 & 02.4 & 0.347 & 19 \\
\hline 10 & Openly shares my feelings & 438 & 40.4 & 375 & 34.6 & 138 & 12.7 & 106 & 09.8 & 28 & 02.6 & 0.771 & 4 \\
\hline 11 & Sexually denies me & 52 & 04.8 & 201 & 18.5 & 263 & 24.2 & 534 & 49.2 & 35 & 03.2 & 0.445 & 15 \\
\hline 12 & $\begin{array}{l}\text { Does everything to avoid } \\
\text { conflict with me }\end{array}$ & 527 & 48.6 & 348 & 32.1 & 127 & 11.7 & 62 & 05.7 & 21 & 01.9 & 0.815 & 3 \\
\hline 13 & $\begin{array}{l}\text { Decides how to resolve our } \\
\text { differences }\end{array}$ & 33 & 03.0 & 411 & 37.9 & 418 & 38.5 & 152 & 14.0 & 33 & 03.0 & 0.580 & 10 \\
\hline 14 & Insults me & 40 & 03.7 & 134 & 12.4 & 241 & 22.2 & 649 & 59.8 & 21 & 01.9 & 0.398 & 16 \\
\hline 15 & $\begin{array}{l}\text { Does not communicate with } \\
\text { me }\end{array}$ & 67 & 06.2 & 204 & 18.8 & 312 & 28.8 & 468 & 43.1 & 34 & 03.1 & 0.469 & 13 \\
\hline 16 & $\begin{array}{l}\text { Believes in give and take in } \\
\text { our discussions }\end{array}$ & 328 & 30.2 & 292 & 36.2 & 206 & 19.0 & 134 & 12.4 & 24 & 02.2 & 0.712 & 7 \\
\hline 17 & Ignores my feelings & 59 & 05.4 & 213 & 19.6 & 277 & 25.5 & 513 & 47.3 & 23 & 02.1 & 0.457 & 14 \\
\hline 18 & $\begin{array}{l}\text { Listens respectfully to my } \\
\text { opinions }\end{array}$ & 591 & 54.5 & 291 & 26.8 & 122 & 11.2 & 60 & 05.5 & 21 & 01.9 & 0.832 & 1 \\
\hline 19 & Beats me & 21 & 01.9 & 78 & 07.2 & 99 & 09.1 & 865 & 79.7 & 22 & 02.0 & 0.325 & 20 \\
\hline 20 & $\begin{array}{l}\text { Leaves scene of our } \\
\text { arguments }\end{array}$ & 202 & 18.6 & 417 & 38.4 & 289 & 26.6 & 147 & 13.5 & 30 & 02.8 & 0.660 & 9 \\
\hline
\end{tabular}

Table 1 presents the research participants' responses in terms of the interactions they undertake during marital crises. It can be seen from the table that the prevalent kind of interaction identified by the participants is that the spouse "listens respectively to my opinions" which possess the highest RSI value of 0.832 and was said to occur always by $54.5 \%$ of the respondents, sometimes by $26.8 \%$ and rarely by $11.2 \%$ while only $05.5 \%$ of the respondents claimed it never occurred. The next popular view of the respondents was that the spouse "is good at resolving our differences" and "does everything to avoid conflict with me" with other very high values of the 
RSI ( 0.830 and 0.815 respectively). The least popular interactions the staff members reported experienced during crises was that the spouse "beats me" with the least RSI value of 0.325 .

In the second approach, the participants' responses to each item were scored in such a way that an "always" response was coded 3 while a "sometimes" response was coded 2 and a "rarely" response was coded 1. Also, a "Never" response was coded zero. The individuals' scores on each of the crisis interaction were obtained by adding up the individual scores on each corresponding items as shown in table 2 in line with Gottman (1999).

Table 2. Items representing different patterns during marital conflicts

\begin{tabular}{lll}
\hline Pattern & Items & Description \\
\hline A & $1,3,5,7,9,14,19$ & Destructive pattern \\
B & $6,10,12,13,16,18$ & Constructive Pattern \\
C & $2,4,8,11,15,17 \& 20$ & Demand-withdraw Pattern \\
\hline
\end{tabular}

Table 2 presents items describing occurrences during different patterns of marital conflict. To determine the prevalent pattern of marital conflict the respondents experienced, the scores of the participants on all the different patterns were subjected to k-means cluster analysis, saving the cluster membership and final cluster centres. The results are presented in Table 3.

Table 3. Final Cluster Centres

\begin{tabular}{lccc}
\hline & \multicolumn{3}{c}{ Cluster } \\
\cline { 2 - 4 } Pattern Aa & 1 & 2 & 3 \\
Pattern Bb & 2.11 & 9.71 & 2.05 \\
Pattern Cc & 5.64 & 10.06 & 14.32 \\
& 4.15 & 11.75 & 9.84
\end{tabular}

Table 3 shows the final cluster centres of the three clusters obtained from the cluster analysis. Ink-mean cluster analysis, a cluster is identified by its nearness to a cluster centre while other clusters are located with their closeness to other cluster centres. It can be seen that Pattern A is the closest to cluster 1 other pattern in cluster 2 Pattern A is still closed but it has been identified as cluster one. However, pattern B is closer than Pattern C and therefore identified as cluster 2 while Pattern $\mathrm{C}$ is closer to cluster 3 and is so identified. The cluster membership which represents the prevalent marital conflict pattern reportedly experienced by each of the participants was saved and was analysed descriptively to obtain the prevalent marital conflict pattern among the research participants under study. The result is presented in Table 4.

Table 4. Prevalent Marital conflict patterns experienced by the staff of Universities in Southwest Nigeria

\begin{tabular}{lcc}
\hline Marital Conflict pattern & Frequency & Percent \\
\hline Pattern A: Destructive & 66 & 06.1 \\
Pattern B: Constructive & 291 & 26.8 \\
Pattern C: Demand-withdraw & 728 & 67.1 \\
Total & 1085 & 100.0 \\
\hline
\end{tabular}

Table 4 shows the patterns of marital conflicts experienced by the staff of selected universities in southwest Nigeria. It can be seen from the table that most of the respondents $(67.1 \%)$ indicated that they experienced demand-withdraw marital conflict pattern while only $26.8 \%$ experienced constructive pattern. $6.1 \%$ indicated that they experienced destructive marital conflict.

3.1.2 Research Question 2: Which Personality Types are Associated with the Patterns of Marital Conflict among the Married Staff of the Selected Universities in Southwest Nigeria

To answer this research question, the participants' responses to each item on PTQ were scored in such a way that a "Strongly Agree" response was coded 4 while an "agree" response was coded 3 and a "disagree" response was coded 2 while a "strongly disagreed" response was coded 1 . The individuals' scores on each of the item cluster on the personality types according to Jung (1971) was obtained by adding up the individual scores on the corresponding items as presented in Table 5 . 
Table 5. Items representing different patterns during marital conflicts

\begin{tabular}{lll}
\hline Personality Types & Items & Description \\
\hline ETT & $1,2,3 \& 4$ & Extroverted Thinking Type \\
EFT & $5,6,7 \& 8$ & Extroverted Feeling Type \\
EST & $9,10,11 \& 12$ & Extroverted Sensational Type \\
EIT & $13,14 \& 15$ & Extroverted Intuitive Type \\
ITT & $16,17,18 \& 19$ & Introverted Thinking Type \\
IFT & $21,22,23 \& 24$ & Introverted Feeling Type \\
IST & $25,26,27 \& 28$ & Introverted Sensational Type \\
IIT & $28,29,30 \& 31$, & Introverted Intuitive Type
\end{tabular}

Table 5 presents items describing respondents' reported attributes. To determine the prevalent pattern of the respondents' attributes and by extension their personality types, the scores of the participants on all the personality attributes were subjected to k-means cluster analysis, saving the cluster membership and final cluster centres. The results are presented in Table 6.

Table 6. Final Cluster Centres

\begin{tabular}{lcccccccc}
\hline & \multicolumn{7}{c}{ Cluster } \\
\cline { 2 - 9 } & 1 & 2 & 3 & 4 & 5 & 6 & 7 & 8 \\
ETT & 6.80 & 6.33 & 7.41 & 7.03 & 8.20 & 6.27 & 4.97 & 2.38 \\
EFT & 6.25 & 7.43 & 7.65 & 6.77 & 8.30 & 6.05 & 4.72 & 1.81 \\
EST & 8.16 & 7.37 & 8.89 & 7.57 & 9.57 & 7.24 & 5.53 & 0.29 \\
EIT & 4.94 & 5.51 & 5.88 & 5.77 & 6.52 & 5.96 & 3.19 & 0.19 \\
ITT & 11.69 & 8.04 & 9.57 & 6.61 & 11.79 & 11.72 & 3.09 & 0.14 \\
IFT & 10.65 & 7.25 & 7.99 & 9.34 & 10.48 & 10.14 & 5.19 & 0.43 \\
IST & 12.84 & 7.25 & 10.87 & 9.49 & 11.94 & 9.79 & 6.22 & 0.14 \\
IIT & 13.98 & 6.98 & 9.74 & 10.19 & 11.61 & 10.79 & 6.69 & 0.38 \\
\hline
\end{tabular}

Table 6 shows the final cluster centres of the eight clusters obtained from the cluster analysis. Ink-mean cluster analysis, a cluster is identified by its nearness to a cluster centre while other clusters are located with their closeness to other cluster centres. It can be seen that ITT and IST are closest to cluster 8; consequently, other low cluster centre values are considered. A close look at cluster 7 shows that ITT is the closest to cluster 7 and can be identified as such. Consequently, Cluster 8 can be identified as IST. Other clusters are identified in this similar manner using cluster centre proximity principles and the identification of the cluster are presented in Table 7.

Table 7. Personality type identification using Cluster Centre Proximity principles

\begin{tabular}{lll}
\hline Cluster & Personality Type & Description \\
\hline 1 & EIT & Extroverted Intuitive Type \\
2 & ETT & Extroverted Thinking Type \\
3 & IFT & Introverted Feeling Type \\
4 & EST & Extroverted Sensational Type \\
5 & IIT & Introverted Intuitive Type \\
6 & EFT & Extroverted Feeling Type \\
7 & ITT & Introverted Thinking Type \\
8 & IST & Introverted Sensational Type \\
\hline
\end{tabular}

The cluster membership which represents the personality type as indicated by each of the participants was saved and was analysed descriptively to obtain the prevalent personality types among the research participants under study. The result is presented in Table 8. 
Table 8. Personality types found prevalent among the staff of the selected universities in Southwest Nigeria

\begin{tabular}{lll}
\hline Personality Type & Frequency & Percent \\
\hline Extroverted Intuitive & 164 & 15.1 \\
Extroverted Thinking & 183 & 16.9 \\
Introverted Feeling & 176 & 16.2 \\
Extroverted Sensational & 107 & 09.9 \\
Introverted Intuitive & 220 & 20.3 \\
Extroverted Feeling & 182 & 16.8 \\
Introverted Thinking & 32 & 02.9 \\
Introverted Sensational & 21 & 01.9 \\
Total & 1085 & 100.0
\end{tabular}

Table 8 shows the personality types found among the staff of selected universities in southwest Nigeria. It can be seen from the table that the largest percentage of the respondents (20.3\%) indicated that they possess Introverted Intuitive personality while $16.9 \%$ and $16.8 \%$ demonstrated Extroverted Thinking and Extroverted Feeling personalities respectively. The smallest percentage demonstrated Introverted Sensational Personality.

3.1.3 Research Question 3: What is the Influence of Each Personality Type on Patterns of Marital Conflict among the Married Staff of Selected Universities in Southwest Nigeria?

To answer this research question, the respondents' patterns of marital conflict was subjected to a Multinomial Logistic Regression (MLR) analysis, given the fact that Patterns of Marital conflict are categorical (nominal). The Patterns of Marital Conflict (PMC) was treated as the criterion variable while the personality type was treated as the explanatory variable. The result is presented in Tables 9.1 to 9.4.

Table 9.1. Model Fitting information

\begin{tabular}{llcccc}
\hline SN & Model & Model Fitting Criteria & \multicolumn{3}{c}{ Likelihood Ratio Tests } \\
\cline { 3 - 6 } & & -2 Log Likelihood & Chi-Square & Df & Sig. \\
\cline { 3 - 6 } 0 & Intercept Only & 203.740 & & & \\
1 & Final & 67.069 & 136.671 & 14 & .000 \\
\hline
\end{tabular}

Table 9.1 presents the model fitting information that tests whether the model gives adequate information about the influence of personality type on Pattern of marital Conflict. Chan (2005) suggested that if the Chi-square value of the final model is significant, it outperforms the null model (that is the first model with intercept only no variable has been added) and therefore it is a better model. This implies that introducing the variable, personality type

will produce a significant influence. To assess the performance, the classification table can be analysed. It is presented in Table 9.2.

Table 9.2. Classification table for observed and predicted values of the number of respondents with different Patterns of Marital Conflict through their personality types

\begin{tabular}{lcccc}
\hline Observed & \multicolumn{4}{c}{ Predicted } \\
\cline { 2 - 5 } & Destructive & Withdraw & Constructive & Percent Correct \\
\cline { 2 - 5 } Destructive & 9 & 51 & 6 & $13.6 \%$ \\
Withdraw & 8 & 639 & 81 & $87.8 \%$ \\
Constructive & 4 & 191 & 96 & $33.0 \%$ \\
Overall Percentage & $1.9 \%$ & $81.2 \%$ & $16.9 \%$ & $68.6 \%$ \\
\hline
\end{tabular}

Table 9.2 shows that the model 1 gives better accuracy for those who experience withdrawal interaction $(87.8 \%)$ during marital conflict than those who experience constructive $(33.0 \%)$ or destructive interaction $(13.6 \%)$. Further, an effort was made to determine the actual influence of personality type on Pattern of marital Conflict through the interpretation of the Likelihood Ratio test and Nagelkerke Pseudo $R^{2}$ values per the recommendations of Field (2005) and Chan (2005). The result is presented in Table 9.3. 
Table 9.3. Likelihood Ratio test and Nagelkerke Pseudo $\mathrm{R}^{2}$

\begin{tabular}{|c|c|c|c|c|c|}
\hline \multirow[t]{2}{*}{ Effect } & Model Fitting Criteria & \multicolumn{3}{|c|}{ Likelihood Ratio Tests } & $\overline{\text { Nagelkerke } \mathrm{R}^{2}}$ \\
\hline & -2 Log Likelihood of Reduced Model & Chi-Square & Df & $\mathrm{P}$ & \\
\hline Intercept & $67.069^{\mathrm{a}}$ & .000 & 0 & - & 0.149 \\
\hline PT & 203.740 & 136.671 & 14 & .000 & \\
\hline
\end{tabular}

The chi-square statistic is the difference in -2 log-likelihoods between the final model and a reduced model. The reduced model is formed by omitting an effect from the final model. The null hypothesis is that all parameters of that effect are 0 .

a. This reduced model is equivalent to the final model because omitting the effect does not increase the degrees of freedom.

Table 9.3 shows the Likelihood Ratio test and Nagelkerke Pseudo $\mathrm{R}^{2}$ values. Specifically, the Likelihood Ratio test shows the contribution of the variable to the model and since the p-value fails to surpass the 0.05 threshold, it can be concluded that the contribution of personality type to marital conflict is significant. Also, Nagelkerke Pseudo $\mathrm{R}^{2}$ values indicate the proportion of the variation in the criterion variable (pattern of marital conflict) that the explanatory variable (personality type) can explain. From the table, it can be seen that the personality type can explain at least $14.9 \%$ of any observed variance in Pattern of marital Conflict of the respondents.

Finally, the parameter estimates were explored to determine which of the personality types would likely result in which the pattern of marital conflict. It should be noted that the destructive pattern is the reference category; consequently, the odds ratio of the personality type concerning destructive interaction in marital conflict cannot be generated. However, the other ones are presented in Table 9.4.

Table 9.4. Parameter estimates for the influence of personality type on Pattern of marital Conflict

\section{Parameter Estimates}

\begin{tabular}{|c|c|c|c|c|c|c|c|c|c|}
\hline \multicolumn{2}{|c|}{ Patterns of Marital Conflict } & \multirow[t]{2}{*}{ B } & \multirow[t]{2}{*}{ Std. Error } & \multirow[t]{2}{*}{ Wald } & \multirow[t]{2}{*}{ Df } & \multirow[t]{2}{*}{ Sig. } & \multirow[t]{2}{*}{$\operatorname{Exp}(B)$} & \multicolumn{2}{|c|}{$95 \%$ Confidence Interval for $\operatorname{Exp}(B)$} \\
\hline & & & & & & & & Lower Bound & Upper Bound \\
\hline \multirow{9}{*}{ Demand-Withdraw } & Intercept & -.118 & .486 & .059 & 1 & .808 & & & \\
\hline & EIT & 2.625 & .578 & 20.607 & 1 & .000 & 13.807 & 4.445 & 42.889 \\
\hline & ETT & 2.720 & .644 & 17.828 & 1 & .000 & 15.187 & 4.296 & 53.693 \\
\hline & IFT & 2.238 & .574 & 15.204 & 1 & .000 & 9.375 & 3.044 & 28.876 \\
\hline & EST & 3.022 & .707 & 18.271 & 1 & .000 & 20.531 & 5.136 & 82.071 \\
\hline & IIT & 2.439 & .552 & 19.519 & 1 & .000 & 11.461 & 3.884 & 33.816 \\
\hline & EFT & 3.485 & .666 & 27.417 & 1 & .000 & 32.625 & 8.851 & 120.254 \\
\hline & ITT & 2.155 & .783 & 7.574 & 1 & .006 & 8.625 & 1.859 & 40.009 \\
\hline & IST & $0^{\mathrm{b}}$ & . & . & 0 & . & . & . & . \\
\hline \multirow{9}{*}{ Constructive } & Intercept & -.811 & .601 & 1.821 & 1 & .177 & & & \\
\hline & EIT & 1.303 & .712 & 3.347 & 1 & .067 & 3.682 & .911 & 14.876 \\
\hline & ETT & 3.584 & .734 & 23.861 & 1 & .000 & 36.000 & 8.548 & 151.621 \\
\hline & IFT & 2.485 & .678 & 13.421 & 1 & .000 & 12.000 & 3.176 & 45.346 \\
\hline & EST & 2.826 & .803 & 12.391 & 1 & .000 & 16.875 & 3.499 & 81.389 \\
\hline & IIT & 1.752 & .669 & 6.851 & 1 & .009 & 5.766 & 1.553 & 21.408 \\
\hline & EFT & 2.667 & .770 & 12.010 & 1 & .001 & 14.400 & 3.186 & 65.086 \\
\hline & ITT & 1.504 & .928 & 2.627 & 1 & .105 & 4.500 & .730 & 27.739 \\
\hline & IST & $0^{\mathrm{b}}$ & . & . & 0 & . & . & . & . \\
\hline
\end{tabular}

a. The reference category is: Destructive.

b. This parameter is set to zero because it is redundant. 
Table 9.4 presents Parameter estimates for the influence of personality type on Pattern of marital Conflict. A close look at the table will indicate that for both demand-withdraw and constructive patterns, IST was set to zero because it was redundant. No value was obtainable for IST in both cases. For the demand-withdraw pattern, all other personality types were found to possess significant values of the Wald statistic implying that they can truly explain why respondents are classified as belonging to the demand-withdraw pattern of marital conflict. However, in the case of constructive pattern, all except EIT and ITT possess significant values of the Wald statistic. Consequently, it cannot be said that personality types can explain the classification of the respondents as belonging to the constructive pattern of marital conflict. Further, the value of Exp (B) refers to the odds that the given personality type will account for the respondents' membership in the pattern of marital conflict. For instance, the odds that respondents with the EIT and EST personality types will experience demand-withdraw marital conflict is greater (13.807 and 20.531 respectively) than experiencing constructive marital conflict (3.682 and 16.875 respectively). This also applies to respondents with EFT and ITT personality types. On the other hand, respondents with ETT, IFT and IIT personality types possess greater odds $(36.00,12.00$ and 5.766 respectively) of experiencing a constructive pattern of marital conflict than a demand-withdraw pattern of marital conflict (4.296, 3.044 and 3.884 respectively).

\section{Discussion}

One major find of this study is that the demand-withdraw pattern was the most prominent, followed by the constructive pattern while the destructive pattern was the least popular. Couples employ the demand-withdraw pattern of behaviour when one partner is seeking change, discussion and resolution of an issue, while the other partner seeks to end or avoid the discussion of the issue altogether. However, as Gottman (1994) found, couples do not hide their feelings from one another. The feelings may either be positive or negative. They argue but have a great time making up. Furthermore, the couples exhibited extra positives than negatives (5:1), as found by Gottman (1994). A possible explanation for this pattern of behavior as shown by this study is that Jung's (1921) personality theory explained how individuals differ in making a decision, process information, communication styles and how they prefer to structure their environments.

The finding of this study also revealed that all eight personality types were found in varying degrees among the staff. Each of these personality types has its behavioural characteristics that are unique and which could engender marital conflict. This explains why all the personality types were associated with the three patterns of marital conflict. This finding is in agreement with the finding of Sandhu and Kapoor (2013), who opined that in applying Jung's orientations to a complete personality, it has been seen that a person is not usually defined by only one of the eight personality types. Instead, the different behavioural functions are in a hierarchical order. One function would have a greater influence and the other an ancillary influence. Typically, according to Jung (1921), a person only makes substantial use of two functions. The other two perform lesser roles.

Consequently, the study showed that the dominant personality types among the staff were Introverted Intuitive, Extroverted Thinking and Extroverted Feeling, while Introverted Sensational type was the least dominant. This finding accentuates the fact that marriage is a relationship that brings persons of different personality characteristics together. Each person comes into the union with his or her individualised characteristics, needs, attitude, values and peculiarities that may be at variance. For example, if an introverted man marries an extroverted wife, their marital interaction might be stressful. An introvert may calm up when talking is called for, whereas an extrovert can talk when they need to listen or think. This couple is most likely to be locked in disagreements when issues confronting them or their children, for instance, call for mutual and effective communication. The introvert prefers to focus on one thing at a time while the extrovert prefers to do things at once.

Although research by Sherman (1981) has shown that people tended to marry similar rather than dissimilar types, the result of this study, however, showed that some of the participants married dissimilar types. Thus, this finding seems to contradict that of Yeakley (1983) which revealed that great resemblances in personality type were considerably linked with active communication in marriage.

The study further revealed that except for Introversion Sensational Type, all other personality types possessed significant values of the Wald statistic for the demand-withdraw pattern. This implies that they can explain why the respondents are classified as belonging to the demand-withdraw pattern of marital conflict. This finding agreed with earlier researches which explained the demand-withdraw from the perspective of individual differences. The individual differences perspective explains that differences in closeness and autonomy can result in personality and attachment needs. In support of this perspective, the demand-withdraw pattern is more 
frequently observed when partners have discrepant intimacy needs that are associated with discrepant attachment styles (Millwood \& Waltz, 2008).

\section{Conclusion}

Based on the outcomes of the analysis, it could be concluded that marriage is a relationship that brings persons of different personality characteristics and intimacy needs together. Also, from the findings of this study, it is obvious that staff in universities in southwest Nigeria have one form of marital conflict or the other. Furthermore, based on the outcomes of the analysis, it could be concluded that all three patterns of marital conflict are being experienced by the staff. The demand-withdraw pattern, however, appeared to be the typical pattern among the staff. Finally, it could be concluded that although certain life experiences are the foundation for the process of maturation, nonetheless maturation in relationships may still be learned. Consequently, if couples are effectively and sufficiently equipped with the necessary knowledge and skills, they can develop a mature outlook about relationships, such as marital relationships.

\section{Recommendations}

Given the above findings and discussion, the following recommendations are suggested:

1. Marriage and Relationship Education (MRE) should be included in the school curriculum at all levels of education in which the concept of healthy relationship skills is imparted to young adults and even teenagers. Teaching this concept will no doubt help participants to identify areas where their personality characteristics will translate to an enduring and satisfying relationship with their marital partners.

2. The Directorate of Online Counselling in collaboration with the Directorate of Information Communication and Technology in the universities should organise regular seminars and workshops for staff members where the necessary skills to communicate and resolve marital conflicts are adequately imparted.

\section{Reference}

Backman, H, Bodenmann, G., \& Gottman, J. M. (1997). A Swiss replication of Gottman's couple typology. Swiss Journal of Psychology, 56(4), 205-216.

Bono, J. E., Boles, T. L., Judge, T. A., \& Lauver, K. J. (2002). The role of personality in task and relationship conflict. Journal of Personality, 70(3), 311-344. https://doi.org/10.1111/1467-6494.05007

Busby, M., \& Holman, T. B. (2009). Perceived match or mismatch on the Gottman conflict styles: Association with relationship outcome variables. Family Process, 48(4), 531-546. https://doi.org/10.1111/j.1545-5300.2009.01300.x

Butler, K. (2006). Can the Gottmans bring empirical rigour to the intuitive world of couples' therapy? Psychotherapy Networker. Retrieved from http://www.psychotherapy.org

Crohan, S. (1996). Marital quality and conflict across the transition to parenthood in African American and White couples. Journal of Marriage and the Family, 58(4), 613-626. https://doi.org/10.2307/353981

Gottman, J. M. (1994). What predicts divorce? The relationship between marital processes and marital outcomes. Hillsdale, NJ: Lawrence Erlbaum Associates.

Gottman, J. M. (1999). The marriage clinic: A scientifically-based marital therapy. New York: W. W. Norton \& Company.

Gottman, J. M., \& Levenson, R. W. (1988). The social psychophysiology of marriage. In P. Noller \& M. A. Fitzpatrick (Eds.), Perspectives on marital interaction (pp. 183-200). Avon, England: Multilingual Matters.

Holman, T. B., \& Jarvis, M. O. (2003). Hostile, volatile, avoiding, and validating couple-conflict types: An investigation of Gottman's couple-conflict types. Personal Relationships, 10(2), 267-282. https://doi.org/10.1111/1475-6811.00049

Jung, C. G. (1971). Psychological types. Princeton, NJ: Princeton University Press.

Kurdek, L. A. (1995). Predicting change in marital satisfaction from husbands' and wives' conflict resolution styles. Journal of Marriage and the Family, 57, 153-164. https://doi.org/10.2307/353824

Mangal, S. K. (2005). Advanced educational psychology (2nd ed.). Prentice-Hall of India: Private Limited New Delhi-110001.

McCarthy, L. A. (2006). Influence of couple conflict type, division of labour, and violated expectations on first-time parents' individual and marital well-being. A dissertation presented to the Graduate School of the 
University of Florida in partial fulfilment of the requirements for the degree of Doctor of Philosophy, University of Florida.

Mulligan, J. (2015). The impact of personality preferences on conflict communication. Breakthrough Newsletter Articles. Breakthrough Consultancy, Ashtown, Roundwood, Co. Wicklow. Ireland. Retrieved from http://www.breakthrough.ie/articleissues/personalitytypevol4no8.htm

Myres, I. B. (1998). Introduction to type (6th ed.). Palo Alto, CA: Consulting Psychologists Press, Inc.

Pasch, L. A., \& Bradbury, T. N. (1998). Social support, conflict, and the development of marital dysfunction. Journal of Consulting and Clinical Psychology, 66(2), 219-230. https://doi.org/10.1037//0022-006X.66.2.219

Pienaar, J. A. (2004). The integration of the Myers and Briggs types indicator in a marriage counselling approach. An unpublished doctoral thesis submitted to the University of South Africa. pp. 1-285.

Raush, H. L., Barry, W. A., Hertel, R. K., \& Swain, M. A. (1974). Communication and conflict in marriage. San Francisco: Jossey-Bass.

Sandhu, T., \& Kapoor, S. (2013). Implications of personality types for emotional regulation in young women. Voice of Research, 1(4).

Sherman, R. G. (1981). Typology and problems in intimate relationships. Research in Psychological Type, 4, 4-23.

Yeakley, F. R. (1983). Implications of communication style research for psychological type theory. Research in Psychological Type, 6, 2-13.

\section{Copyrights}

Copyright for this article is retained by the author(s), with first publication rights granted to the journal.

This is an open-access article distributed under the terms and conditions of the Creative Commons Attribution license (http://creativecommons.org/licenses/by/4.0/). 